\title{
Microstructure and Mechanical Properties of Severely Deformed Mg-4.5Al-1.0Zn Alloy Processed by Asymmetric Rolling on Ingot and Twin Roll Cast Strip
}

\author{
Liting Luo ${ }^{a}$, Xibing Gong ${ }^{b}$, Juzi Li ${ }^{b, c, *}$, Suk Bong Kang ${ }^{d}$, Jae Hyung Cho ${ }^{d}$ \\ ${ }^{a}$ Wuhan College, Wuhan 430079, China \\ ${ }^{b}$ University of Alabama, Tuscaloosa 35487, USA \\ ${ }^{c}$ Gemmological Institute, China University of Geosciences, Wuhan 430074, China \\ ${ }^{d}$ Korea Institute of Materials Science, Changwon 641010, Korea
}

Received: May 26, 2015; Revised: October 5, 2015; Accepted: December 14, 2015

\begin{abstract}
The twin roll cast Mg-4.5Al-1.0Zn alloy sheets, processed by asymmetric rolling and subsequent annealing were investigated. The asymmetric rolling on $\mathrm{Mg}-4.5 \mathrm{Al}-1.0 \mathrm{Zn}$ ingot was also studied for comparison in terms of microstructure, texture and mechanical properties of the sheets. The results can be summarized as follows. The rolled sheets show intensively deformed band structures and fine grains due to dynamic recrystallization. After annealing at $375^{\circ} \mathrm{C}$ for $1 \mathrm{hr}$, both the twin roll casted and ingot processed sheets show the fine equiaxed grains with around $9 \mu \mathrm{m}$ in mean diameter. The twin roll casted magnesium alloy sheet shows superior tensile strength and low elongation compared to the ingot cast one. The results of this work suggest that asymmetric rolling can improve the formability of magnesium alloy and the technique could be extended to enhance the sheet qualities of different alloys in jewelry industry.
\end{abstract}

Keywords: Wrought magnesium alloy; Asymmetric rolling; Microstructure; Texture; plasticity

\section{Introduction}

Magnesium (Mg) alloys are becoming increasingly popular due to their high specific strengths and have great potential for jewelry applications ${ }^{1}$. However, the high manufacturing expense of wrought $\mathrm{Mg}$ alloy and poor formability and strength at room temperature limit the industrial application of $\mathrm{Mg}$ alloys. The improvement of the ductility and strength of $\mathrm{Mg}$ alloys is being considered as a major challenge in further extending their applications ${ }^{2,3}$.

Some methods are effective to improve the strength and formability of $\mathrm{Mg}$ alloys, such as grain refinement ${ }^{4-8}$, texture weakening ${ }^{6,7}$, chemical modification ${ }^{9}$, rapid solidification ${ }^{10}$, and etc. Twin roll casting (TRC), which combines continuous casting and direct hot rolling into a single step, has an advantage of one-step processing for flat rolled products. TRC process also has beneficial effect on resulting microstructure such as reducing segregation, improving inclusion size distribution and refining microstructural homogeneity ${ }^{2,3}$.

Plastic deformation contributes to enhance the strength of the $\mathrm{Mg}$ alloys however the strong basal texture is known to be detrimental to the their formability ${ }^{4,5}$. It is important to weaken the basal texture to achieve better plasticity ${ }^{6,7}$. Recently, the grain refinement, weak texturing and deviated basal textures were observed during asymmetric rolling (AR $)^{4-7}$. $\mathrm{AR}$ is a processing carried out at different rotation speeds for upper and lower rolls so that intense shear deformation can be imparted throughout the sheet thickness ${ }^{5}$. It is thus of interest to apply $\mathrm{AR}$ technique in processing $\mathrm{Mg}$ alloy sheets with improved formability for jewelry application.

*e-mail: juzili69@gmail.com
The objective of this study is to investigate the AR technique on ingot and TRC. The materials selected here is $\mathrm{Mg}-4.5 \mathrm{Al}-1.0 \mathrm{Zn}$ alloy, which has improved elevated temperature properties and corrosion resistance ${ }^{7}$. The alloy is also representative of the AZ alloy family with an intermediate $\mathrm{Al}$ content. A commercial rolling machine was used to fabricate Mg-4.5Al-1.0Zn sheets.

\section{Experimental procedures}

The melted Mg-4.5Al-1.0Zn alloy with a temperature of $700{ }^{\circ} \mathrm{C}$ was flowed down into a steel mold with a size of $200 \mathrm{~m}$ by $160 \mathrm{~mm}$ by $25 \mathrm{~mm}$. A block with the size of $3.7 \mathrm{~mm}$ in thickness and $180 \mathrm{~mm}$ in width was then machined. For the TRC, same melted Mg-4.5Al-1.0Zn alloy was applied and the detailed process is introduced from the previous research ${ }^{7}$. Some visible cracks were observed on the surface of the Mg-4.5Al-1.0Zn TRC strip. In the current research, the surface finish was conducted to remove the cracks. Both the ingot block and TRC strip were preheated to $350{ }^{\circ} \mathrm{C}$ for $30 \mathrm{~min}$ for homogenization, and then rolled at the same temperature with the rollers heated to $250{ }^{\circ} \mathrm{C}$. This process was repeated twice to reduce the strip thickness down to $2.2 \mathrm{~mm}$. The $2.2 \mathrm{~mm}$-thick sheets were annealed at $350{ }^{\circ} \mathrm{C}$ for $30 \mathrm{~min}$ to relieve the inner stresses. Then the sheets were rolled to the final thickness of $0.55 \mathrm{~mm}$ by eight passes at $300^{\circ} \mathrm{C}$, by AR on ingot and TRC strip, respectively. The AR process was conducted at a speed ratio of 1.2 while the lower rotation speed of roller was $5 \mathrm{~m} / \mathrm{min}$. The surface of the rollers was lubricated every two passes to prevent the adhesion of $\mathrm{Mg}$ alloys to the rollers and the processed 
sheets showed good appearance without obvious defects such as edge or surface cracks. The warm-rolled sheets were subjected to a final annealing at $350{ }^{\circ} \mathrm{C}$ for $60 \mathrm{~min}$.

Fabricated Mg-4.5Al-1.0Zn samples were prepared for microstructural observation with standard metallographic procedures including sectioning, mounting, grinding with $\mathrm{SiC}$ paper up to a grit size of 1000 . Specimens closed to the middle of the transverse direction (TD) plane of the rolled sheets were used for analysis. To prepare the smooth surface for etching, electro-polishing was applied on the specimen surfaces with a solution of $\mathrm{HClO}_{4}(40 \mathrm{ml})$ and ethanol $(400 \mathrm{ml})$ at a voltage of about $10 \mathrm{~V}$. To reveal the microstructures, polished specimens were then etched with a solution of picric acid ( $5 \mathrm{~g})$, acetic acid $(5 \mathrm{ml})$, distilled water $(10 \mathrm{ml})$, and ethanol $(100 \mathrm{ml})$. The etched metallographic samples were then examined using optical microscope (OM). Transmission electron microscope (TEM) observations were made in the middle region of the final ARed-sheet using a JEM-2100F TEM operating at $200 \mathrm{kV}$. Thin foils for the TEM observations were prepared by a twin-jet electronpolisher using a solution of $\mathrm{HClO}_{3}(50 \mathrm{ml})$, butanol $(350 \mathrm{ml})$ and methanol $(600 \mathrm{ml})$. Electron backscattered diffraction (EBSD) was carried out on the annealed sheets, using samples for test were prepared by mechanical and electropolishing similar to that used for OM samples. The EBSD measurements were performed using a step size of $1 \mu \mathrm{m}$ on a JEOL-7001F1 FE-SEM equipped with the HKL Channel 5 data acquisition software. The misorientation used in defining grain boundaries was $15^{\circ}$. Tensile tests were carried out for the annealed sheets according to the ASTM E8 standard, using samples with a gauge length of $12.5 \mathrm{~mm}$ and a width of $3 \mathrm{~mm}$ along the rolling direction (RD). The tests were conducted on a standard universal testing machine (Instron 4206) at room temperature with a normal strain rate of about $2 \times 10^{-3} \mathrm{~s}^{-1}$. In order to ensure reproducibility of the tensile results, three specimens were tested in each case.

\section{Results and discussion}

\subsection{Microstructures}

Fig. 1 shows the OM microstructures of the Mg4.5Al-1.0Zn alloy from the casting (Fig. 1(a)) and TRC (Fig. 1(b)). Both ingot and TRC strip are characterized by equiaxed dendrite structure with dispersed particles located on the interdendritic boundaries. The microstructure of $\mathrm{Mg}-4.5 \mathrm{Al}-1.0 \mathrm{Zn}$ consists mainly of $\alpha-\mathrm{Mg}$ matrix (hexagonal crystal structure, $\mathrm{HCP}$ ) and few $\beta-\mathrm{Mg}_{17} \mathrm{Al}_{12}$ (body centered cubic, BCC) precipitates. The grain size of the ingot is around $50-100 \mu \mathrm{m}$, while the grain size for TRC strip is about $10 \mu \mathrm{m}$. The grain refinement of the TRC strip could be attributed to the rapid cooling. The cooling rate in solidification process has a great influence on the microstructure of the alloys. The cooling rate in TRC is about $80^{\circ} \mathrm{C} / \mathrm{s}$ to $200^{\circ} \mathrm{C} / \mathrm{s}$, which is much higher than those undergone during conventional ingot casting process ${ }^{2}$. In addition, the ingot sample presents larger size of these dispersed particles compared with that of ingot sample. Wang et al. ${ }^{3}$ also compared the particle size between ingot and TRC samples, and the TRC sample presented much finer particle size.

Fig. 2 shows the SEM micrograph of TRC strip. The eutectics and intermetallic compounds were seen in the interdendritic region as shown. Fig. 2 also shows the corresponding $\mathrm{Mg}, \mathrm{Al}, \mathrm{Ca}, \mathrm{Mn}$ and $\mathrm{Zn}$ dot-mapping images of $\mathrm{Mg}-4.5 \mathrm{Al}-1.0 \mathrm{Zn}$ alloy strip. The eutectics and intermetallic compounds in the interdentritic region mainly contained $\mathrm{Mg}$ and $\mathrm{Al}$ elements, and some phases contained a little $\mathrm{Ca}$ or $\mathrm{Mn}$ elements ${ }^{11}$. The effects of $\mathrm{Ca}$ addition on the microstructure and mechanical properties of AZ91 Mg alloy have been studied ${ }^{12}$. The results show that the $\mathrm{Ca}$ addition can refine the microstructure, reduce the quantity of $\mathrm{Mg}_{17} \mathrm{Al}_{12}$ phase, and form new $\mathrm{Al}_{2} \mathrm{Ca}$ phase in $\mathrm{Mg}$ alloy.

Fig. 3 shows the optical microstructure of rolled sheets at $350{ }^{\circ} \mathrm{C}$ by AR with different rolling reductions $(43 \%, 68 \%$, and $75 \%$ ). The microstructure of the rolled ingot is also studied for comparison, as can be seen in Fig. 3(a, c, e). After the rolling reduction of $43 \%$, the dendrite structure is generally broken and large elongated grains are seen (Figs. 3(a, b)). Very few grains formed by dynamically recrystallization (DRX) are found. The twinning is found and it is important to the plastic deformation of $\mathrm{Mg}$ alloys. On further reduction to $68 \%$ (Figs. 3(c, d)), more deformation bands or shear bands extensively are developed, and spacing between deformation bands or shear bands become narrower. More DRXed grains are continuously nucleated in the twinned regions. It is expected that recrystallization took place during warm rolling. When the final rolling reduction of $75 \%$ is reached (Fig. 3(e, f)), a
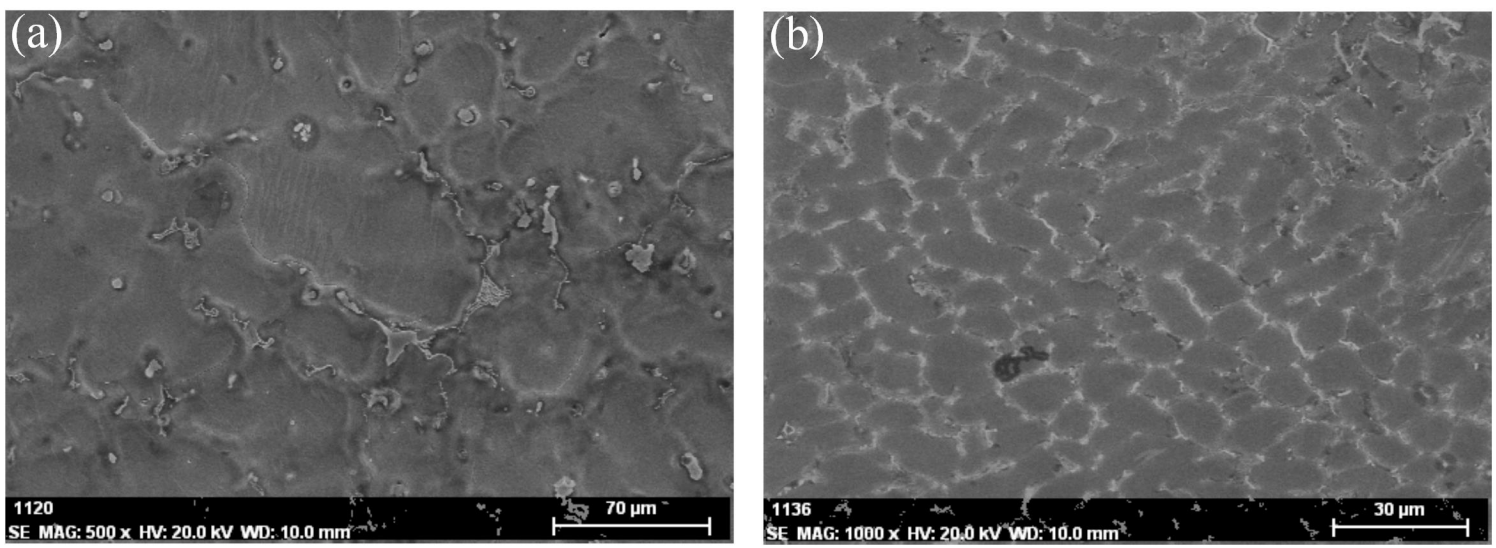

Fig. 1. Microstructure of Mg-4.5Al-1.0Zn Mg alloy: (a) Ingot and (b) TRC. 

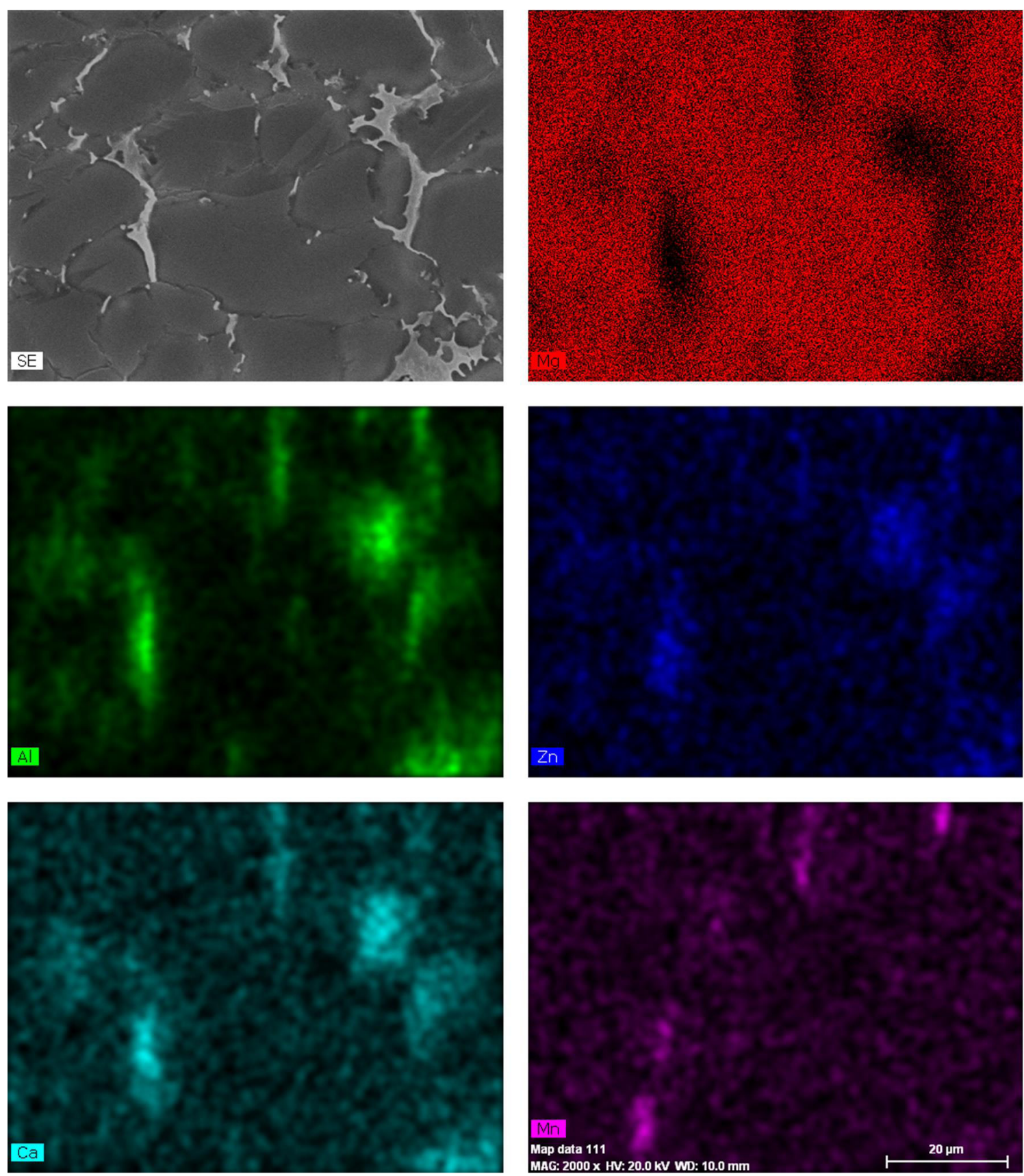

Fig. 2. SEM micrographs of specimens and X-ray mapping results for the TRC strip.

more homogeneous microstructure was obtained. Moreover, a remarkable DRXed microstructure was observed. It also can be seen that unidirectional shear bands are gradually developed, as can be clearly seen in Fig. 3(e, f). Finer grains are observed along the shear band. It indicates that intense shear deformation is formed during the AR. From the comparison of the plastic deformation on ingot and TRC strip, the ingot presents more homogeneous microstructure and almost no elongated grains are existed; while small DRXed grains develop at grain boundaries and the entire microstructure becomes significantly inhomogeneous for TRC strip, which is mainly attributed to the uneven rate of recrystallization at different oriented grains. The inhomogeneous microstructure is mainly attributed to the uneven rate of recrystallization among different oriented grains. It could demonstrate that the ingot Mg-4.5Al-1.0Zn has more tendencies to formed small grains through DRX. It is clear that DRX is much more sensitive in the ingot, and thus the microstructure is quickly replaced by fine DRXed grains. On the other hand, TRC Mg-4.5Al-1.0Zn is less sensitive to DRX, which are still present with large grains in the microstructure. Wang et al., ${ }^{13}$ stated that the shear band-like fine grains 

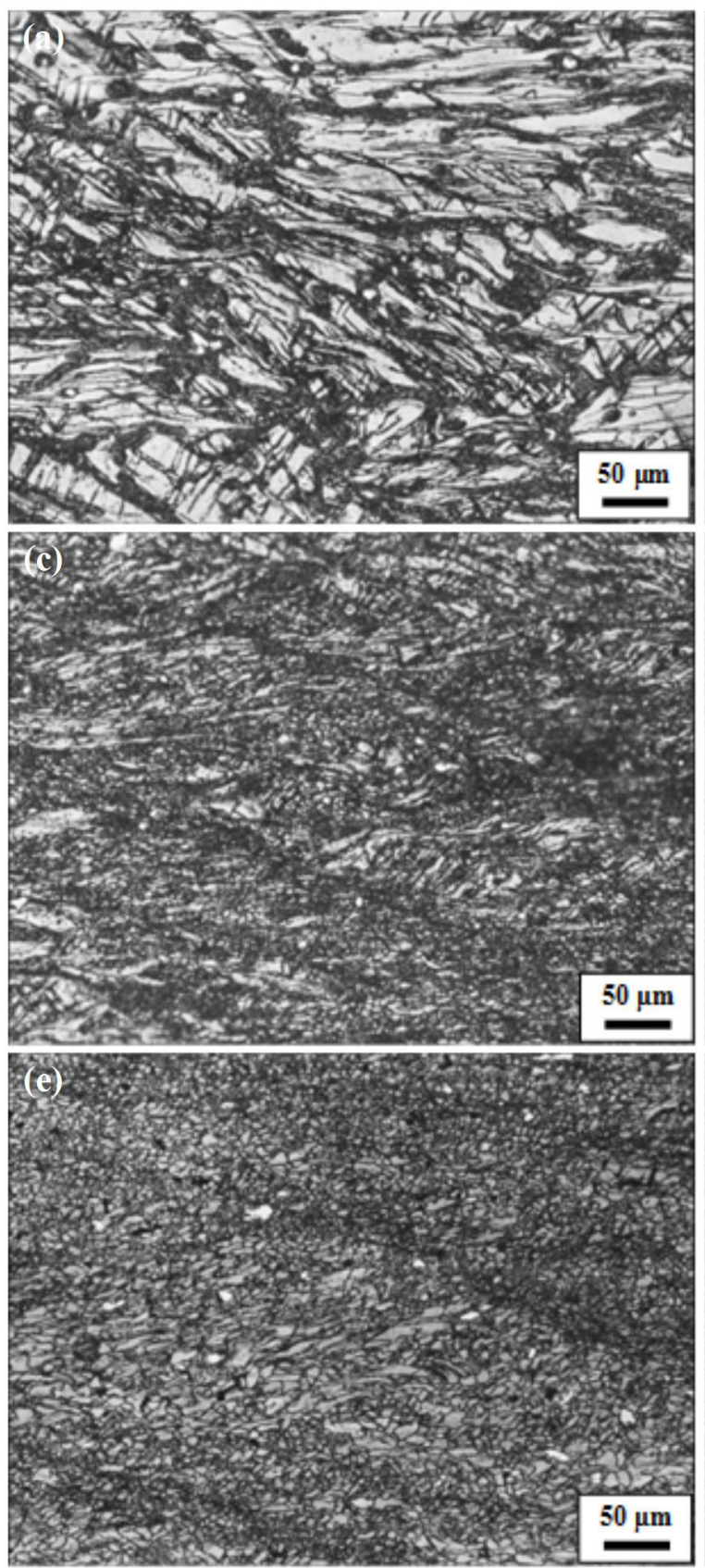
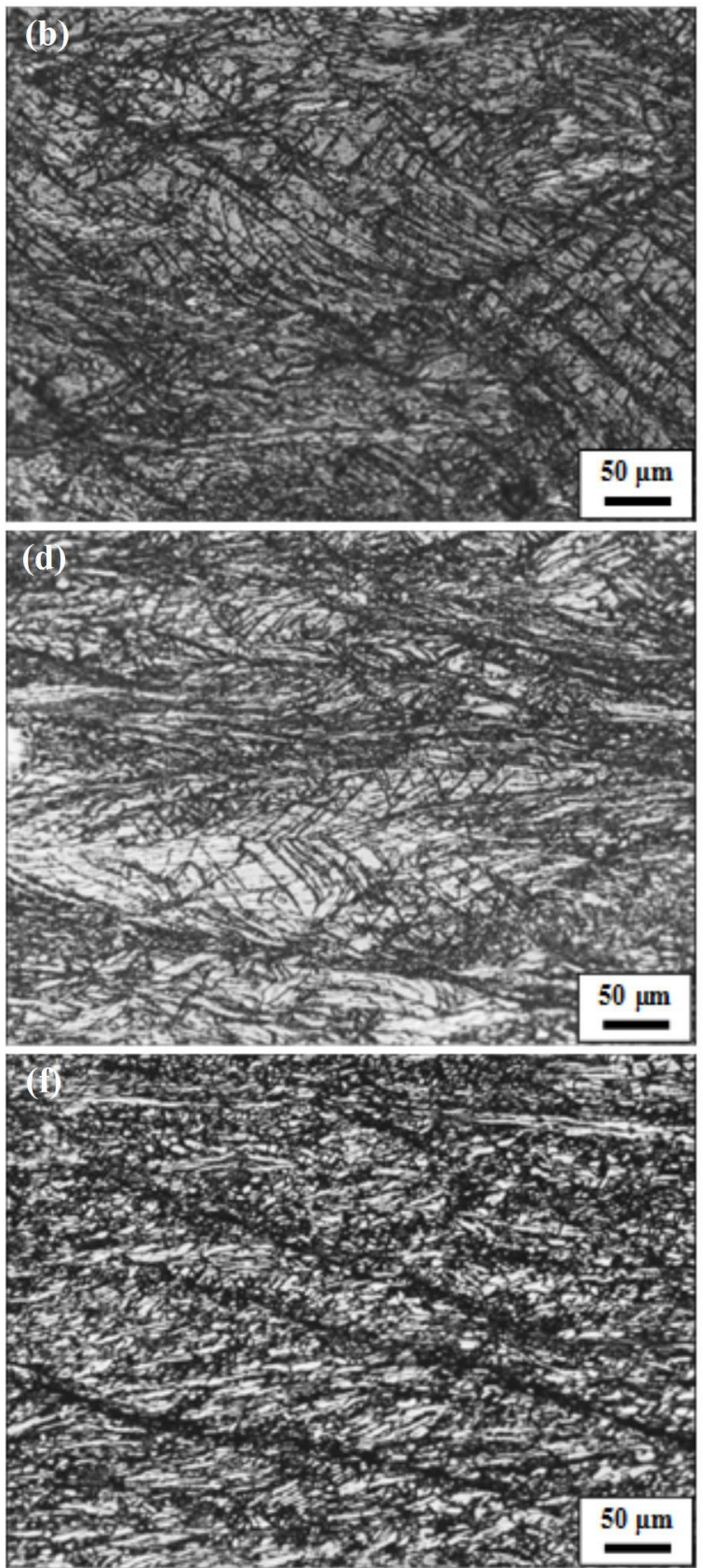

Fig. 3. Typical microstructure of Mg-4.5Al-1.0Zn after AR at $300{ }^{\circ} \mathrm{C}$ after (a, b) $43 \%$, (c, d) $68 \%$, and (e, f) $75 \%$ rolling reductions by $(a, c, e)$ from ingot and (b, d, f) from TRC, respectively. Longitudinal sections with RD parallel to scale bar.

have a close relationship to the DRXed grains nucleated in the twinned regions.

Compared to those of the equal speed rolling (ESR) sheet of Mg-4.5Al-1.0Zn, the microstructures developed in the AR-processed sheet are more homogeneous and depict a higher percentage of DRXed grains. The occurrence of the DRX was attributed to high-dislocation density accumulation and high temperature rise of a deforming sheet due to large plastic deformation in AR compared with conventional rolling.

Wang et al., ${ }^{13}$ studied the ESR on TRC strip, and found that the microstructural evolution during warm rolling process is mainly characterized by deformation bands or shear bands, and no evident twins and DRXed grains are observed. Therefore, it is suggested that deformation mode for TRC sample is mainly dominated by dislocation multiplication mechanism. However, the twinning and DRX are found from both ingot and TRC samples. The difference of the plastic deformation and different alloy could attribute to the different microstructures. The $\{10-12\}$ tensile twinning or $\{10-11\}-\{10-12\}$ double-twinning is most easily activated in $\mathrm{Mg}$, and occur extensively at the early and later stage during 
compressive test or rolling at low and moderate temperature ranges for the $\mathrm{Mg}-\mathrm{Al}-\mathrm{Zn}$ system alloys ${ }^{13}$.

The microstructures of the rolled sheets were examined using TEM, and a typical example is shown in Fig. 4. Both ingot and TRC samples present well-defined subgrain boundaries and the average size of the DRXed grains is less than $1 \mu \mathrm{m}$. Also high density dislocations are clearly observed, and it demonstrates that dislocation multiplication slips, in particular, non-basal $<\mathrm{c}+\mathrm{a}>$ slips on pyramidal slip system extensively occurred. For the comparison between ingot and TRC, the ingot sample shows well-defined grain boundaries owing to the fully DRX took place, as can be seen shown in Fig. 4(a). The result of the DRX is consistent with the observation from $\mathrm{OM}$.

Fig. 5 shows the microstructures after annealing of the sheets processed by (a) ingot and (b) TRC, respectively. The annealed sheets present fine and equiaxed grains, indicating that homogeneous nucleation and grain growth during static crystallization. The shear bands tend to act as favored sites for nucleation during annealing. The sheets sheet exhibiting nearly homogeneous grains, the AR-processed sheet exhibits finer grains along lines which might correspond to the locations of the unidirectional shear bands previously existed in the rolled state.

In order to achieve quantitative analysis of the grain size and size distribution, Image Pro Plus was applied to study the size distribution in both the ingot and TRC samples.
The minimum diameter was set as $3 \mu \mathrm{m}$ in order to exclude the noise from image processing. The distribution of the grain sizes was obtained as shown in Fig. 6 for the grain size in the range of 3 to $25 \mu \mathrm{m}$. It can also be noted that the major range of powder diameters is around 3 to $10 \mu \mathrm{m}$, while the mean overall diameters of the grain size is $8.9 \mu \mathrm{m}$ for the ingot sample and $8.7 \mu \mathrm{m}$ for the TRC sample. Similar mean grain sizes are presented between both samples. While Wang et al., ${ }^{13}$ studied the distribution of the grain size and reported the significant difference of the grain sizes: $11.2 \mu \mathrm{m}$ for the ingot and grain size of $7.8 \mu \mathrm{m}$ of the TRC. It is explained that particles located on grain boundaries would restrain the migration of grain boundaries, which is one of the main reasons for obtaining the homogeneous fine-grained microstructure. The grain refinement mainly occurs in the shear bands because the main portion of the plastic deformation is thought to take place in the shear bands during rolling. A smaller grain size in the shear bands indicates that more intense plastic deformation concentrates on the shear bands during the AR process. Moreover, twinning could not be observed in the both ingot and TRC sheets after annealing.

\subsection{Crystallographic texture}

Warm rolling generally gives rise to a strong basal texture, which exhibits low formability at near room temperature because the basal slip systems hardly become active. Therefore, it is important to change or weaken the
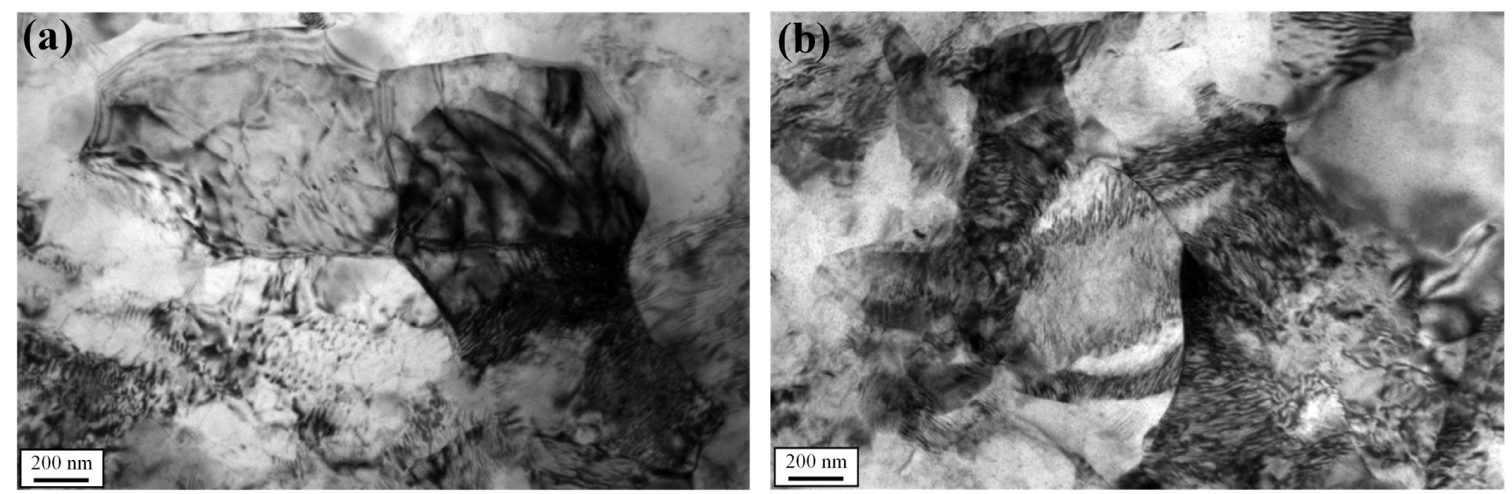

Fig. 4. TEM micrograph of rolled sheets showing DRX-ed grains: (a) Ingot, and (b) TRC.
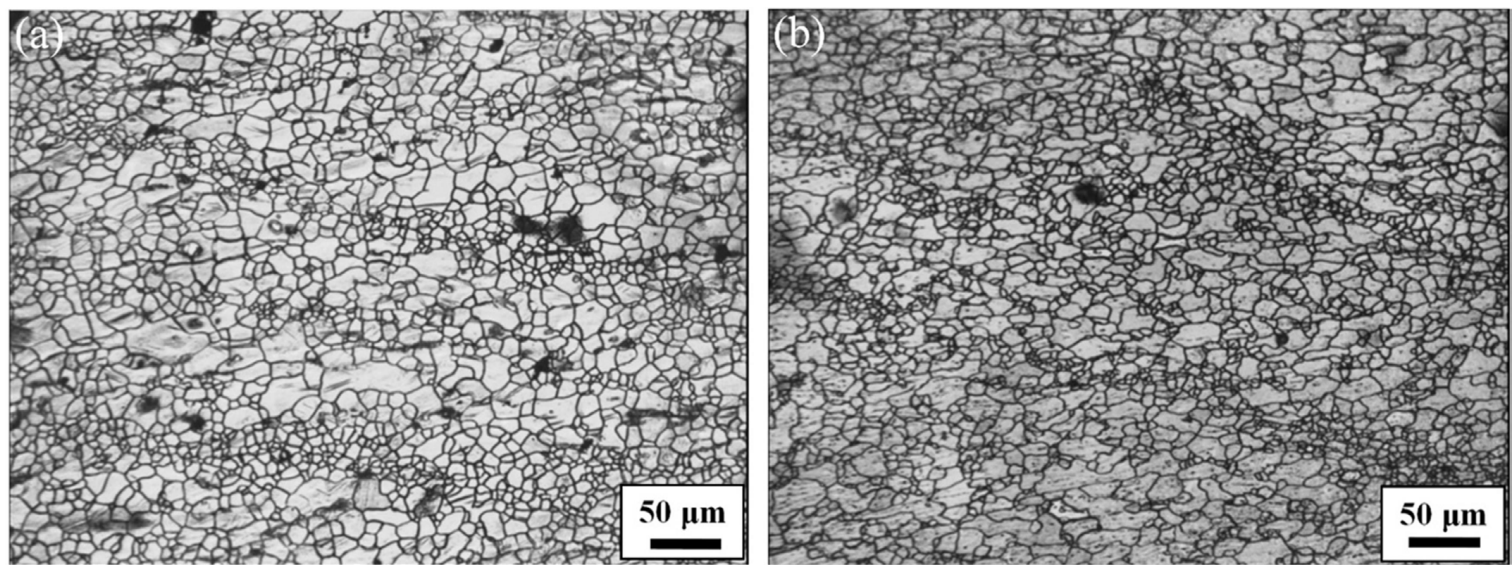

Fig. 5. OM microstructure of annealed sheets: (a) Ingot, and (b) TRC. 

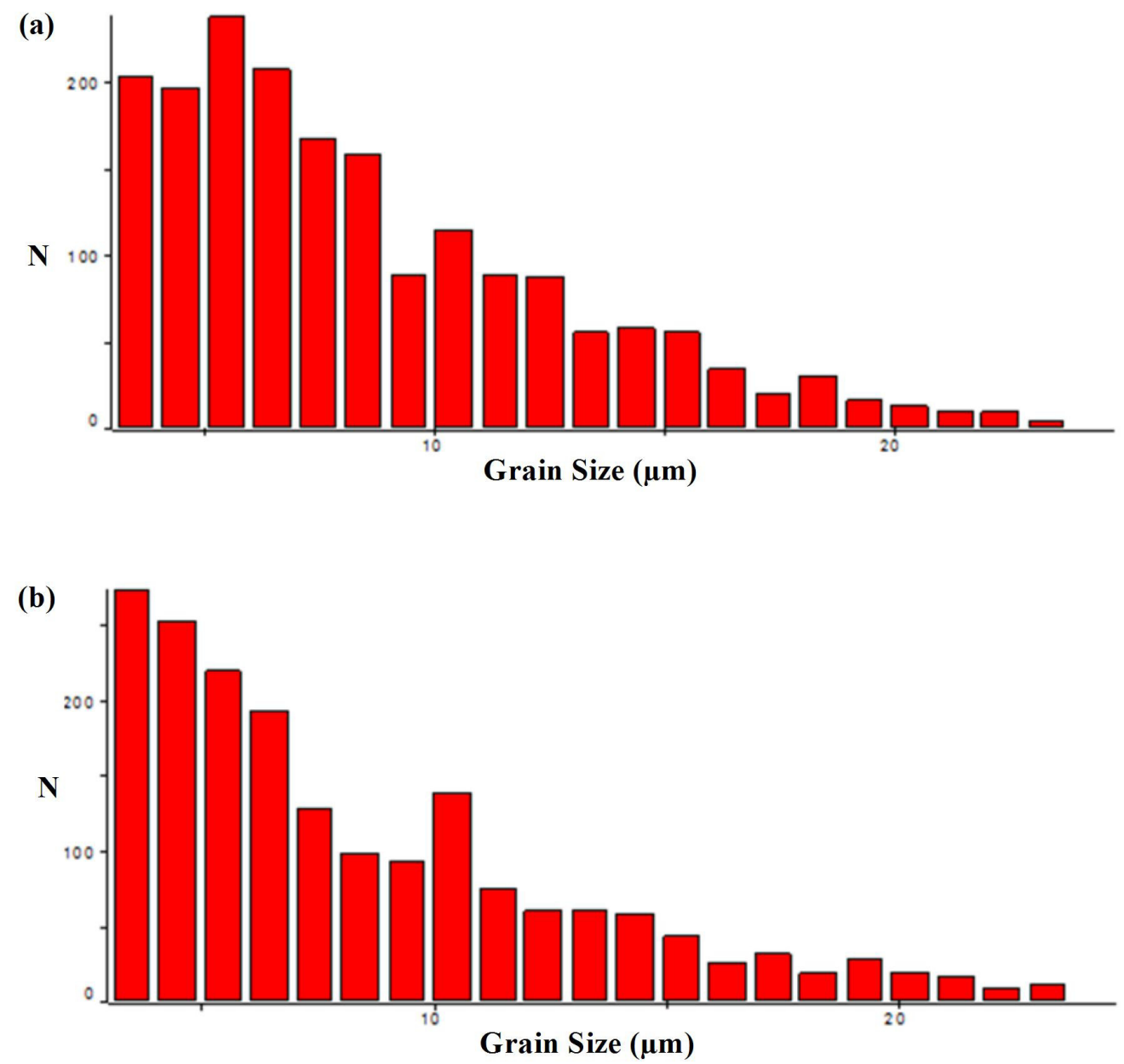

Fig. 6. Histograms of grain sizes: (a) ingot and (b) TRC.

basal texture for formability improvement. During rolling, (0002) basal planes align parallel to the RD-TD plane, and an intense basal plane texture is formed. The rolled $\mathrm{Mg}$ alloy exhibits poor room temperature formability. The $\{0002\}$ pole figures were calculated from EBSD data, as can be seen from Fig. 7. For both sheets, the textures can be considered as basal fiber textures with the $<\mathrm{c}>$-axis approximately normal to the sheet plane. Both ingot and TRC sheets show a splitting of the basal pole with the peaks deviated from the ND towards RD. The double-peak basal textures shown are most likely a result of shear banding ${ }^{6,7}$. The inclination of the basal texture induces the less normal anisotropy in sheet and decreases the difficulty in deformation at room temperature. The maximum intensity of the basal texture is much lower for the TRC processed sheet. The present investigation indicates that the weakening and splitting effect of texture play an important role in achieving desired mechanical properties. The nearly identical colored grains mean that the misorientations between these grains are not large. The observed shear bands could have originated from clustering of first and second generation twins. Shear bands have basal planes parallel to the shear plane leading to some weakening of the basal texture in sheet material ${ }^{4,5}$.
Fig. 8 shows the misorientation of the Mg-4.5Al-1.0Zn alloy processed by ingot and $\mathrm{TRC}$, respectively. The annealing of the as-rolled sheets resulted in fully recrystallized microstructures and most grains had misorientation angles of $30 \pm 5^{\circ}$. It is also noted that small but obvious increase in the frequency of high angle boundaries (HAGBs) between $80^{\circ}$ and $90^{\circ}$. During annealing, high angle boundaries are preferred, because they are thermodynamically more stable ${ }^{8,14}$.

\subsection{Mechanical properties of annealed sheets}

According to the tensile test, the TRC sample shows higher yield stress (YS) and ultimate tensile stress (UTS) as well as comparative elongation than those of ingot sample, as seen in Table 1. It could demonstrate that the TRC sample exhibits superior mechanical properties compared to ingot sample after warm rolling and subsequent annealing. The high strength of TRC sample is mainly due to the particle strengthening and solid solubility strengthening as well as fine-grain strengthening mechanisms resulting from the more and finer primary dispersed particles and smaller grain size, respectively ${ }^{13}$. However, the TRC sample shows slightly low elongation than that of the annealed ingot sample. Wang et al. explained that the small space between particles in TRC sample would easily induce the connection of holes 
(a)

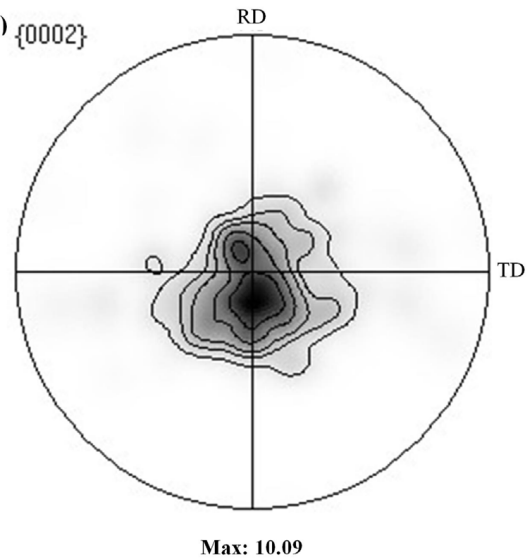

(b) $\{0002\}$

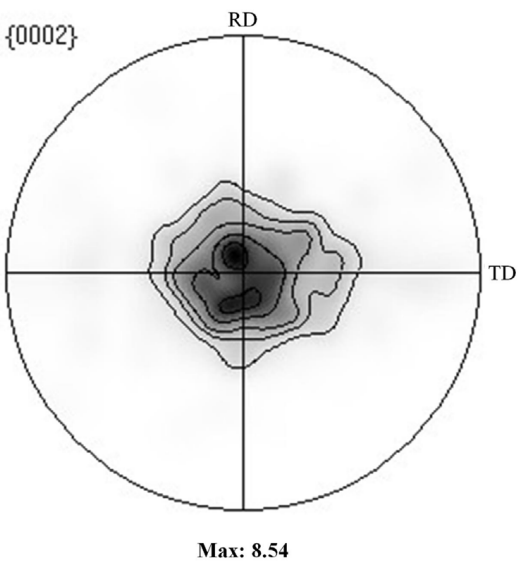

Fig. 7. Pole figures of annealed sheets: (a) ingot and (b) TRC.
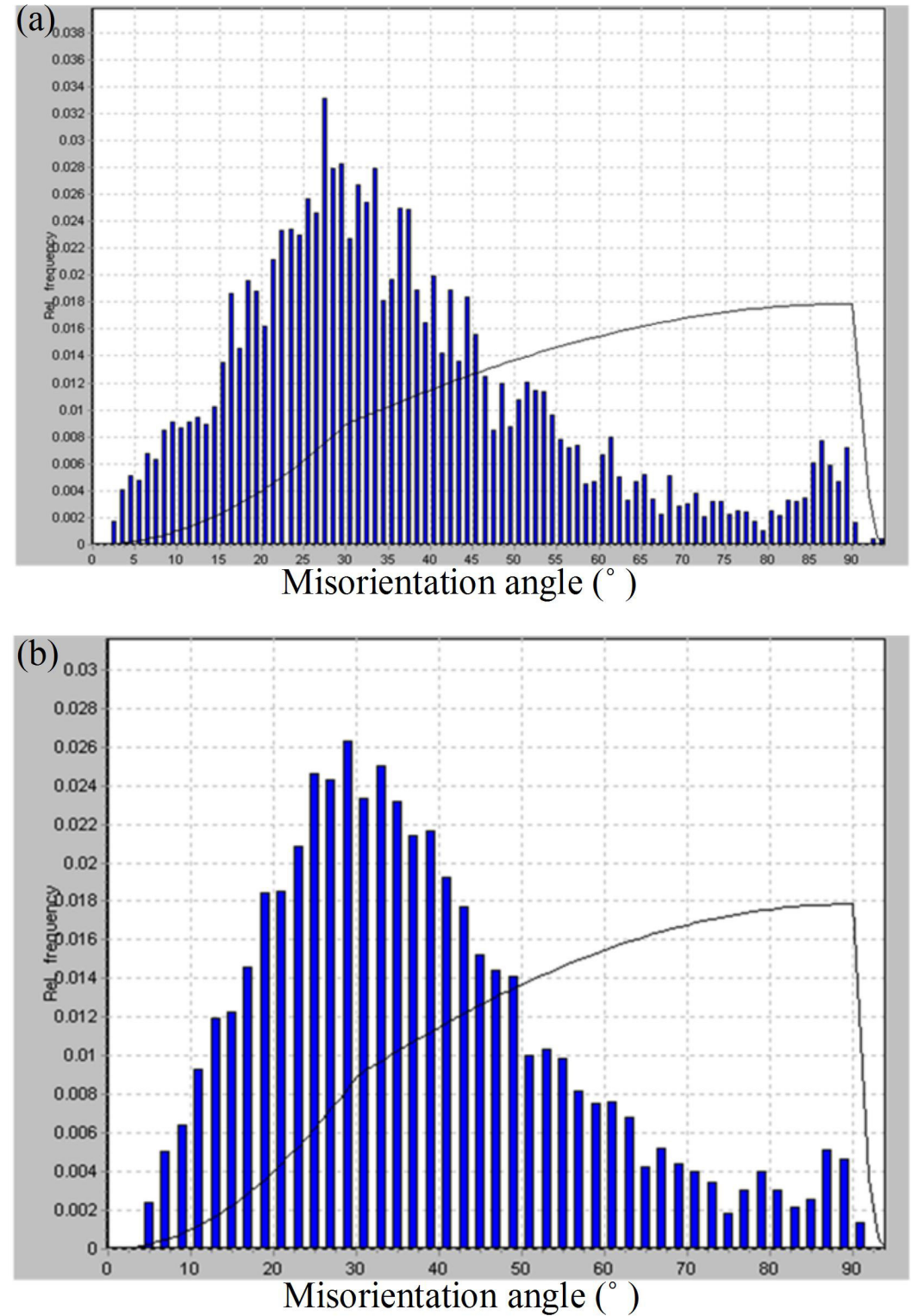

Fig. 8. Misorientation of the annealed AR sheets: (a) from ingot, and (b) from TRC. 
Table 1. Tensile properties of the annealed sheets.

\begin{tabular}{|c|c|c|c|c|c|c|}
\hline \multirow[b]{2}{*}{ Method } & \multicolumn{2}{|c|}{ YS (MPa) } & \multicolumn{2}{|c|}{ TS (MPa) } & \multicolumn{2}{|c|}{ Elongation (\%) } \\
\hline & Average & $\begin{array}{l}\text { Standard } \\
\text { deviation }\end{array}$ & Average & $\begin{array}{l}\text { Standard } \\
\text { deviation }\end{array}$ & Average & $\begin{array}{l}\text { Standard } \\
\text { deviation }\end{array}$ \\
\hline Ingot & 200 & 3.5 & 263 & 1.4 & 17.4 & 1.0 \\
\hline $\mathrm{TRC}$ & 187 & 2.0 & 270 & 2.0 & 15.0 & 0.6 \\
\hline
\end{tabular}

initiated by dislocation interaction during the later stage of deformation, which may result in the lower elongation ${ }^{13}$.

Generally, the plasticity of the $\mathrm{Mg}-4.5 \mathrm{Al}-1.0 \mathrm{Zn}$ sheets is improved for both the ingot and TRC samples. The increase of the elongation can be mainly attributed to the grain refinement and texture weakening in AR. For the Mg-4.5Al-1.0Zn alloy sheets, the grain structures are effectively refined after warm rolling. As it is well known, the yield stress as a function of grain size can be represented as Hall-Petch relationship ${ }^{6-8}$. Meanwhile, the mechanical properties in the present study might be also attributed to the texture weakening effects.

\section{Conclusions}

Asymmetric rolling on ingot and TRC is capable of making thin $\mathrm{Mg}-4.5 \mathrm{Al}-1.0 \mathrm{Zn}$ sheets for jewelry application. In this study, the microstructure evolution, texture, and mechanical properties were examined experimentally. The comparison between ingot and TRC were examined. The major findings are summarized as follows.

\section{References}

1. Lance N. Thermodynamically stable superstructures in binary alloys. In: Meeting of the Four Corners Sections of the APS, 2009 Oct 23-24. Abstract \#K2.006. http://adsabs.harvard.edu/ abs/2009APS..4CF.K2006N

2. Park SS, Bae GT, Kang DH, Jung IH, Shin KS, Kim NJ. Microstructure and tensile properties of twin-roll cast $\mathrm{Mg}$ Zn-Mn-Al alloys. Scripta Materialia. 2007; 57(9):793-796. doi:10.1016/j.scriptamat.2007.07.013

3. Wang S, Kang SB, Cho JH. Effect of hot compression and annealing on microstructure evolution of ZK60 magnesium alloys. Journal of Materials Science. 2009; 44(19): 5475-5484.

4. Cho JH, Jeong SS, Kim HW, Kang SB. Texture and microstructure evolution during the symmetric and asymmetric rolling of AZ31B magnesium alloys. Materials Science and Engineering A. $2013 ; 566$ : 40-46.

5. Cho JH, Kim HW, Kang SB, Han TS. Bending behavior, and evolution of texture and microstructure during differential speed warm rolling of AZ31B magnesium alloys. Acta Materialia. 2011; 59(14): 5638-5651. doi:10.1016/j.actamat.2011.05.039

6. Gong X, Kang SB, Li S, Cho JH. Enhanced plasticity of twin-roll cast ZK60 magnesium alloy through differential speed rolling. Materials and Design. 2009; 30(9): 3345-3350. doi:10.1016/j. matdes.2009.03.040

7. Gong X, Li H, Kang SB, Cho JH and Li S. Microstructure and mechanical properties of twin-roll cast Mg-4.5Al-1.0Zn alloy sheets processed by differential speed rolling. Materials and Design. 2010; 31(3): 1581-1587.
(1) The AR-processed sheets are characterized by the unidirectional shear bands. After annealing, fine grains are expected to form along the position of the previously developed shear bands. The AR-processed sheet possesses a high fraction of fine-grained region. Both ingot and TRC processed sheets present the grain size of $9 \mu \mathrm{m}$ after annealing.

(2) The AR-processed sheet presents a basal fiber texture with splitting along the $\mathrm{RD}$. The inclination of the basal texture could be attributed to the shear deformation in AR.

(3) The annealed TRC specimens exhibit tensile strength of $270 \mathrm{MPa}$, yield strength of $187 \mathrm{MPa}$, and elongation of $15.0 \%$. The enhancement of the elongation can be mainly attributed to the weakening of the basal texture and grain refinement. The ingot specimen presents lower strengths but a little higher of the elongation.

8. Chang LL, Cho JH, Kang SB. Microstructure and mechanical properties of twin roll cast AM31 magnesium alloy sheet processed by differential speed rolling. Materials and Design. 2012; 34 : 746-752.

9. Al-Samman T, Li X. Sheet texture modification in magnesiumbased alloys by selective rare earth alloying. Materials Science and Engineering A. 2011;528(10): 3809-3822. doi:10.1016/j. msea.2011.01.080

10. Zhang HJ, Zhang DF, Ma CH, Guo SF. Improving mechanical properties and corrosion resistance of $\mathrm{Mg}$-6Zn-Mn magnesium alloy by rapid solidification. Materials Letters. 2013; 92 45-48. doi:10.1016/j.matlet.2012.10.051

11. Chen H, Kang SB, Yu H, Kim HW, Min G. Microstructure and mechanical properties of Mg-4.5 Al-1.0 Zn alloy sheets produced by twin roll casting and sequential warm rolling. Materials Science and Engineering A. 2008;492: 317-326.

12. Wang Q, Chen W, Zeng X, Lu Y, Ding W, Zhu Y, Xu X, Mabuchi M. Effects of Ca addition on the microstructure and mechanical properties of AZ91 magnesium alloy. Journal of Materials Science. 2001; 36(12): 3035-3040.

13. Wang Y, Kang SB and Cho JH. Microstructure and mechanical properties of Mg-Al-Mn-Ca alloy sheet produced by twin roll casting and sequential warm rolling. Journal of Alloys and Compounds. 2011; 509(3): 704-711. doi:10.1016/j. jallcom.2010.07.183

14. Jager A, Luka P, Gartnerova V, Haloda J, Dopita M. Influence of annealing on the microstructure of commercial Mg alloy AZ31 after mechanical forming. Materials Science and Engineering A. 2006; 432(1-2):20-25. doi:10.1016/j.msea.2006.06.070 